\title{
Climate variability, predictability and climate risks: a European perspective
}

\author{
Heinz Wanner • Martin Grosjean • \\ Regine Röthlisberger · Elena Xoplaki
}

Received: 24 March 2006 / Accepted: 24 May 2006 / Published online: 8 November 2006

(C) Springer Science + Business Media B.V. 2006

The aim of climate research is to increase our knowledge about the nature of climate and the causes of climate variability and change. Increasing our understanding of the physical processes on various spatial and temporal scales will ultimately reduce uncertainty and improve our capabilities to predict climate on monthly to seasonal timescales and allow us to separate the anthropogenic and natural causes of long term climate change.

Current estimates of past and future climate change, projections of future greenhouse gas (GHG) emissions and their effects are subject to various uncertainties. Climate policymaking faces a wide range of significant scientific and socio-economic uncertainties pointing to the question of whether scientific understanding is sufficient to justify particular types of technical and political actions (Lempert et al. 2004; Manning et al. 2004).

The public and policy-makers need current and accurate estimates of climate change projections, uncertainty in future costs, benefits and impacts of potential choices, design of greenhouse gas mitigation, preparation for adaptation, and the funding level of research across many related disciplines. (Webster 2003; Webster et al. 2003). Without this information, policy discussion is unavoidably divided in two opposing parties, those who support calls for immediate action, i.e., reduction of human-caused greenhouse gases emissions, and those who wish not to take action because they are waiting for more information (e.g., Reilly et al. 2001). In addition, due to the potential social disruptions and high economic costs of emissions reductions, a vigorous debate has developed concerning the magnitude and the nature of the projected climate changes and whether they will actually lead to serious impacts (e.g., Mahlman 1997). Thus, climate-change policy formulation constitutes a great challenge since it introduces the problem of decision-making under uncertainty (Webster et al. 2003 and references therein).

The uncertainty analysis seems at first rather "uncomplicated", in reality however many empirical, methodological, institutional and philosophical challenges arise. Additionally, the optimal decisions of today do not only depend on the current uncertainties but also on the change in the uncertainties and our past and future responses. Policy decisions are therefore

H. Wanner · M. Grosjean · R. Röthlisberger · E. Xoplaki $(\square)$ NCCR Climate, University of Bern, Erlachstrasse 9a, 3012 Bern, Switzerland e-mail: xoplaki@giub.unibe.ch 
better modeled as sequential decisions under uncertainty (Hammitt et al. 1992; Manne and Richels 1995; Webster 2002). The sequential decision process adapts to new knowledge and responds to new information and events. This flexible decision process requires a careful adhesion to the uncertainties' change whilst continuously integrating new knowledge on climate system processes and socio-economic consequences and reactions (Webster 2003; Webster et al. 2003).

The quantification of uncertainty requires a model describing the fundamental and well known multi-sectoral (scientific as well as socio-economic) processes that contribute to the results. Furthermore, the use of consistent and well-documented methods to develop uncertainty estimates will allow the changes in our understanding to be tracked through time. In this case, a useful proportion of the uncertainties could be captured, although the parameters and assumptions of the model will still include some uncertainty (Webster 2003). Hence, a significant part of our uncertainty about past and future climate change will be unavoidable (Webster et al. 2003).

The importance of adequately quantifying and communicating uncertainty has been recently accepted in the climate research community. The authors for the Third Assessment Report (TAR) of the Intergovernmental Panel on Climate Change (IPCC) were encouraged to quantify uncertainty as much as possible (Moss and Schneider 2000).

However, various limitations characterise these attempts to quantify uncertainty: (a) Climate observations were not used to constrain the uncertainty in climate model parameters (Wigley and Raper 2001). (b) By using only one Atmosphere-Ocean General Circulation Model (AOGCM), uncertainties in climate model response are reduced to uncertainty in a single scaling factor for optimizing the model's agreement with observations (Stott and Kettleborough 2002). (c) The IPCC emissions scenarios have been used as of equal likelihood (Wigley and Raper 2001). (d) Some studies analysed the uncertainty only in the climate system response without characterizing the economic uncertainty except through individual IPCC emissions scenarios, by estimating uncertainty in future climate change only applied to specific IPCC emissions scenarios (Allen et al. 2000; Knutti et al. 2002; Stott and Kettleborough 2002). (e) The uncertainty analysis was in no case done under a policy scenario leading to stabilisation of GHG concentrations. (f) Uncertainty estimates for reconstructions of past climate (e.g., Mann et al. 1999; Luterbacher et al. 2004; Xoplaki et al. 2005) usually do not take into account dating uncertainty of the climate proxies (natural and documentary), loss of signal confidence within the twentieth century calibration period, uncertainties in the instrumental data (e.g. Brohan et al. 2006 and references therein), assumptions about signal stationarity, proxies exhibiting an unquantified degradation in reliability, reduction of sample replication, etc. (Esper et al. 2005).

Across all areas of climate change, it is found that uncertainty tends to increase when moving from global to regional scales. Regional information is clearly highly relevant to policy, but generally is much less precise and can be ambiguous and confusing. Thus, a careful balance is needed when considering the scale at which policy relevant information can be provided (Manning et al. 2004). The assessment of potential regional impacts of climate change has, up to now, relied on data from coarse resolution AOGCMs, which do not resolve spatial scales of less than $\sim 300 \mathrm{~km}$ (Mearns et al. 2001).

According to Dessai and Hulme (2004) there are two different sources of uncertainty, the "epistemic" and the "stochastic". Epistemic uncertainty originates from incomplete knowledge of processes that influence events. These sources of uncertainty can be reduced by further studying the climate system, improving the state of knowledge, etc. Stochastic sources of uncertainty are those that are considered "unknowable" knowledge - items such as variability in the system, the chaotic nature of the climate system, and the indeterminacy of human systems Springer 


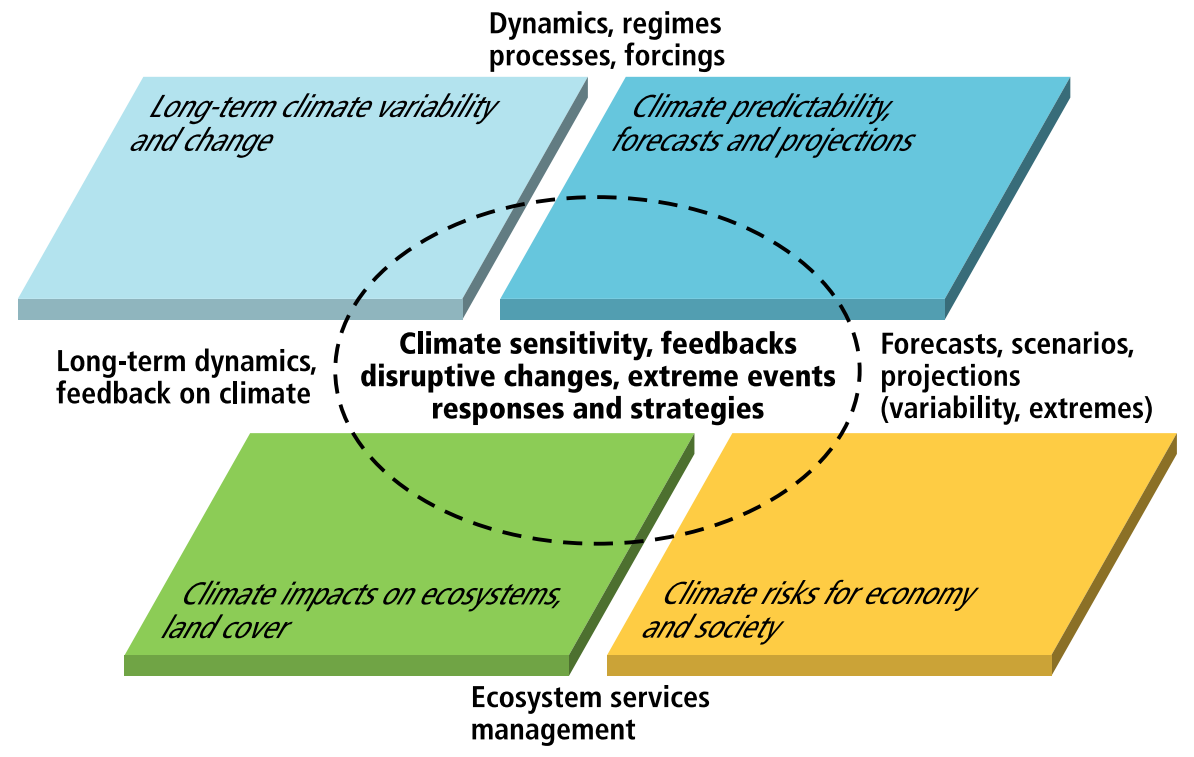

Fig. 1 Structure of NCCR Climate and major fields of inter-Work-Package (in different colours) collaboration and interaction

(Dessai and Hulme 2004). Further, the likelihood of various scenarios will likely change as soon as a prediction is made, because society begins to react (and adapt) and therefore change the outcome in ways that were not incorporated into the prediction (Sarewitz et al. 2003).

The sources of uncertainty in climate forecasting that have to be taken into consideration, as suggested at the IPCC Workshop on Communicating Uncertainty and Risk (Manning et al. 2004), are: (a) Uncertainty in anthropogenic forcing due to different emission paths ("scenario uncertainty"). (b) Uncertainty due to natural variability, encompassing internal chaotic climate variability and externally driven (e.g., solar, volcanic) natural climate change ("natural variability"). (c) Uncertainty in the climate system's response to external forcing due to incomplete knowledge of feedbacks and timescales in the system ("response uncertainty") (Allen et al. 2004).

The National Centre of Excellence in Research on Climate (NCCR Climate), which is based in Bern, Switzerland, aims at increasing our knowledge of the climate system by carrying out interdisciplinary research on its variability and future change, climate impacts and their financial evaluation, and climate policies (Figure 1). It is a scientific network bringing together 130 researchers from 13 Swiss partner institutions (http://www.nccr-climate.unibe.ch/). The NCCR Climate is a long-term research programme that started in $2001 .^{1}$

The core theme of NCCR Climate is: "Climate variability, predictability, and climate risks". It builds on three interlinked research fields that frame the research activities:

\footnotetext{
${ }^{1}$ The NCCR Climate in its second phase (2005-2009) is building on the scientific and institutional achievements of the first phase and focuses on: (1) European past climate variability covering the last 1000 years; (2) Climate predictability, global to regional climate processes, and projections on seasonal to interannual scales and more accurate predictions and extreme events; (3) Ecosystem impacts and adaptation, assessing implications for ecosystems and evaluating strategies for the management of forests and agriculture; (4) Climate risks addressing questions on the potential perspectives for regional and global post-Kyoto climate policies and the vulnerability and adaptation costs of regional and global economies to global climate change.
} 
1. What is the nature of past, current and future climate? What is the sensitivity of the climate system (including the internal variations and extremes) to anthropogenic and natural perturbations? What are the feedbacks between the atmosphere, the ocean, the cryosphere, land surfaces and the anthroposphere?

2. What are the forced climate impacts on ecosystems, economy and society? What is the likelihood of rapid transitions and changes with disruptive impacts? What is the role of extreme climate events on ecosystems, the economy and society?

3. What are the options and strategies for the management of ecosystems, economic systems and societal systems to respond to such climate changes and to reduce vulnerability?

Within the structure of the NCCR climate research, there are three geographical scales (Switzerland including the greater Alpine area, Europe and global) and three temporal scales (the last 500 years, the present and the 21st century).

The issues targeted in NCCR Climate require work at a wide range of spatial and temporal scales as well as the combination and integration of results from observational, experimental and modelling studies. Developing methodologies and providing an environment to work across the boundaries of different scales and methods is a priority area in climate research. It is intellectually and technically challenging, but a prerequisite to address the complex nature of the research issues in an adequate manner.

This book (special issue) compiles seven consecutive and integrative chapters, which (i) address some of the aforementioned common scientific challenges in current climate and climate impact research and (ii) synthesize the interdisciplinary research across the large thematic umbrella of the NCCR Climate. The scientific voyage starts with two selected problems of atmospheric and climate research, that address (i) different scales in time from the past to the future with different types of data availability (Raible et al. 2006), and (ii) reducing uncertainty of climate predictions and projections (Schwierz et al. 2006). We then move on to the topic of future climate change impacts on natural and managed ecosystems. The main challenge of climate impacts research is to consolidate the large scale projections to regional or local scales of climate variability and change, which can then be integrated into more specialised climate impact models (Calanca et al. 2006). Impacts are not limited to ecosystems but encompass the entire social, technological and economic systems (Fuhrer et al. 2006). Thus, building a modelling framework where the climate system and the energyeconomy-environment systems communicate interactively with each other (Bahn et al. 2006) is fundamental in order to assess future development paths, strategies and options for climate change mitigation policies (Viguier et al. 2006). Finally, it is the society, at different hierarchical levels with different organizational forms and institutions, which makes the decisions and assesses the future failure or success of any climate change policy (Bürgenmeier et al. 2006).

Raible et al. (2006) assessed the natural climate variability on interannual to decadal timescales by using AOGCMs, state-of-the-art regional circulation models in combination with multiproxy climate reconstructions from regional to continental scales. The reconstructions reveal pronounced interdecadal variations, which seem to "lock" the atmospheric circulation in quasi-steady long-term patterns over multi-decadal periods, which partly control the continental alpine temperature and precipitation variability. In contrast, the climate model simulations indicate some substantial differences to the observations, indicating that the teleconnectivity between modeled climate variables is weaker than in observations however, in the future these teleconnections seem to be more stable. This partial disagreement between the reconstructions and the model simulations implies the need for better instrumental and more numerous natural/documentary proxy data sets, further improvement in reconstruction 
methods and multi-model ensemble approaches (combination of regional and global models) (e.g., Yoshimori et al. 2005; Goosse et al. 2005, 2006; Raible et al. 2006).

Today's climate models capture the essence of the large-scale aspects of the current climate and its considerable natural variability reasonably well on time scales ranging from one day to decades. Despite this significant achievement, the models show weaknesses that add uncertainty to the very best model projections of human-induced climate changes.

Schwierz et al. (2006) present an overview of the uncertainties in climate model projections that arise from various sources. They identified uncertainties stemming from the complexity and non-linearity of the climate system, its irregular evolution and the changing climate sensitivity, the emission scenarios selection and their implications for the radiative forcing, and the inevitably incomplete and inadequate representation of the climate system in a weather or climate model. The latter uncertainty can be separated into that which is connected with the model equations representing the climate system interactions, the limited representation of physical processes due to the low resolution of the models and the limited knowledge of some physical processes including the non-linear interactions between the climate components. Schwierz et al. (2006) report that a hierarchy of models is a powerful approach to estimate and assess uncertainty, while the combination of different kinds of models of different complexity with an overlap between the model evaluations can contribute to the quantification and reduction of uncertainties from future climate model projections.

Calanca et al. (2006) combined simulations with a state-of-the-art Global Circulation Model (GCM) complemented by an experiment with a high-resolution spatially distributed hydrological model in order to quantify the impact of climate change and to reveal regional differences in the response, both across the alpine region as well as within individual river basins in Switzerland. They found that GCMs alone cannot capture the detailed regional scale results, demonstrating the danger of a simple extrapolation of GCM results and underlining the importance of a highly resolved hydrological model for the quantitative assessment of the regional impacts of climate change. Current spatial resolution of GCMs is too coarse to adequately represent areas of complex topography and land use change (Calanca et al. 2006).

Fuhrer et al. (2006) assessed climate risks on ecosystems using simulations for present climate with a 50-km Regional Climate Model (RCM) with boundary conditions from a GCM control experiment and compared the model output with observations. Climate risks arise from complex interactions between climate, environment, social and economic systems. They represent combinations of the likelihood of climate events and their consequences for society and the environment. The assessment of climate risks depends on both the ability to simulate extreme events in various scales and the understanding of the responses of the target system. The projections of climate risks are dependant on the quality of the link between larger-scale climate simulations and small-scale effects. Extreme climate events are often related to large-scale synoptic conditions, but the scales at which impacts occur can vary from local to regional (Fuhrer et al. 2006).

In order to obtain an integrated assessment of climate policies, Bahn et al. (2006) established a two-way coupling between the economic module of a well-established integrated assessment model and an intermediate complexity "3-D" climate model. The coupling is achieved through the implementation of an advanced "oracle based optimisation technique" which permits the integration of information coming from the climate model during the search for the optimal economic growth path. They showed that further applications of this method could include the coupling of an economic model and an advanced climate model that could describe the carbon cycle. Additionally, the spatial resolution of the climate model allows the construction of regional damage functions or in other words, the ability to link climate feedbacks with economic activity (e.g. agriculture). A further step is the coupling of 
a macro-economic growth module with a detailed techno-economic model, in addition to the coupling with a moderate complexity climate model (Bahn et al. 2006).

Viguier et al. (2006) used an optimal economic growth model, a multi-region bottom-up process model and a multi-region computable general economic equilibrium (CGE) model for the assessment of climate change policies. Their assessment reveals the important effect of endogenising technological learning by early investments in research and development $(R \& D)$ activities and demonstration and deployment (D\&D) programs. These programs could support the development and diffusion of cleaner technologies in the long term, and influence the strategic behaviour of climate policy makers and ultimately the success of international climate-policy. The strategic behaviour of the different countries towards the Kyoto protocol is related with the connected costs and the ability of the governments to afford these costs.

Bürgenmeier et al. (2006) explore the reasons behind the reluctant application of economic instruments of climate change. They stress the need for interdisciplinary research linking economic theory and empirical testing to deliberative political procedures. They found that the promotion of economic policies of climate change has to be completed by social policies to capture the ethical aspects. Additionally, the problem of the social acceptance of economic instruments of climate change can be overcome by using a) Conventional models that consider the environment, either through public goods theory or through property rights theory and b) More global models featuring relationships between economics, the biosphere and social aspects in order to come closer to the concept of sustainable development.

The understanding of the likelihood of future climate requires further and repeated analysis of the up-to-date combined knowledge on the climate and socio-economic systems (Webster et al. 2003).

Acknowledgements The NCCR Climate is supported by the Swiss National Science Foundation. We would like to thank Prof. George Zaimes from the School of Natural Sciences at the University of Arizona for his constructive comments on the document, Dr. Paul Della-Marta from the Institute of Geography at the University of Bern for proofreading the English text and Mr. Andreas Brodbeck from the Institute of Geography at the University of Bern, for drawing the figure.

\section{References}

Allen MR, Booth BBB, Frame DJ, Gregory JM, Kettleborough JA, Smith LA, Stainforth DA, Stott PA (2004) Observational constraints on future climate: distinguishing robust from model-dependent statements of uncertainty in climate forecasting. In: Manning et al. (eds) Describing scientific uncertainties in climate change to support analysis of risk and of options May 2004 IPCC workshop report. IPCC Working Group I Technical Support Unit, Boulder, Colorado, USA, pp 53-57(Available at: http://www.ipcc.ch/)

Allen MR, Stott PA, Mitchell JFB, Schnur R, Delworth TL (2000) Quantifying the uncertainty in forecasts of anthropogenic climate change. Nature 407:617-620

Bahn O, Drouet L, Edwards NR, Haurie A, Knutti R, Kypreos S, Stocker TF, Vial JP (2006) The coupling of optimal economic growth and climate dynamics. Clim Change, DOI: 10.1007/s10584-006-9108-4 (this issue)

Brohan P, Kennedy JJ, Harris I, Tett SFB, Jones PD (2006) Uncertainty estimates in regional and global observed temperature changes: a new dataset from 1850. J Geophys Res DOI: 10.1029/2005JD00654

Bürgenmeier B, Baranzini A, Ferrier C, Germond-Duret C, Ingold K, Perret S, Rafaj P, Kypreos S, Wokaun A (2006) Economics of climate policy and collective decision making. Clim Change, DOI: 10.1007/s10584006-9147-x (this issue)

Calanca P, Roesch A, Jasper K, Wild M (2006) Global warming and the summertime evapotranspiration regime of the alpine region. Clim Change, DOI: 10.1007/s10584-006-9103-9 (this issue)

Dessai S, Hulme M (2004) Does climate adaptation policy need probabilities? Climate Policy 4:107-128

Esper J, Wilson RJS, Frank DC, Moberg A, Wanner H, Luterbacher J (2005) Climate: past ranges and future changes. Quat Sci Rev 24:2164-2166

Springer 
Fuhrer J, Beniston M, Fischlin A, Frei C, Goyette S, Jasper K, Pfister C (2006) Climate risks and their impact on agriculture and forests in switzerland. Clim Change, DOI: 10.1007/s10584-006-9106-6 (this issue)

Goosse H, Renssen H, Timmermann A, Bradley RS (2005) Natural and forced climate variability during the last millennium: A model-data comparison using ensemble simulations Quat Sci Rev 24:1345-1360

Goosse H, Renssen H, Timmermann A, Bradley RS, Mann ME (2006) Using paleoclimate proxy-data to select and optimal realisation in an ensemble of simulations of the climate of the past millennium Clim Dynam. DOI: $10.1007 / \mathrm{s} 00382-006-0128-6,27: 165-184$

Hammit JK, Lempert RJ, Schlesinger ME (1992) A sequential-decision strategy for abating climate change. Nature 357:315-318

Knutti R, Stocker TF, Joos F, Plattner GK (2002) Constraints on radiative forcing and future climate change from observations and climate model ensembles. Nature 416:719-723

Lempert R, Nakicenovic N, Sarewitz D, Schlesinger ME (2004) Characterizing climate-change uncertainties for decision-makers. Clim Change 65:1-9

Luterbacher J, Dietrich D, Xoplaki E, Grosjean M, Wanner H (2004) European seasonal and annual temperature variability, trends, and extremes since 1500. Science 303:1499-1503

Mahlman JD (1997) Uncertainties in projections of human-caused climate warming. Science 278:1416-1417

Mann ME, Bradley RS, Hughes MK (1999) Northern hemisphere temperatures during the past millennium: inferences, uncertainties, and limitations. Geophys Res Lett 26:759-762

Manne AS, Richels RG (1995) The greenhouse debate: economic efficiency, burden sharing and hedging strategies. Energy J 16:1-37

Manning et al. (eds.) (2004) Describing scientific uncertainties in climate change to support analysis of risk and of options, may 2004 ipcc workshop report. IPCC Working Group I Technical Support Unit, Boulder, Colorado, USA, pp 138. (Available at: http://www.ipcc.ch/)

Mearns LO, Hulme M, Carter TR, Leemans R, Lal M, Whetton PH (2001) Climate scenario development. Chapter 13 In: Houghton J, et al. (eds), Clim Change 2001: The Scientific Basis, Intergovernmental Panel on Climate Change, Cambridge University Press, pp 739-768

Moss RH, Schneider SH (2000) In: Pachauri R, Taniguchi T, Tanaka K (eds), Guidance papers on the cross cutting issues of the third assessment report. World Meteorological Organization, Geneva, pp 33-57

Raible CC, Casty C, Luterbacher J, Pauling A, Esper J, Frank DC, Büntgen U, Roesch AC, Tschuck P, Wild M, Vidale PL, Schär C, Wanner H (2006) Climate variability - observations, reconstructions, and model simulations for the atlantic-european and alpine region from 1500-2100 AD. Clim Change, DOI: 10.1007/s10584-006-9061-2 (this issue)

Reilly J, Stone PH, Forest CE, Webster MD, Jacoby HD, Prinn RG (2001) Climate change: uncertainty and climate change assessments. Science 293:430-433

Sarewitz D, Pielke RA Jr., Keykhah M (2003) Vulnerability and risk: some thoughts from a political and policy perspective. Risk Analysis 23:805-810

Schwierz C, Appenzeller C, Davies HC, Liniger MA, Müller W, Stocker TF, Yoshimori M (2006) Challenges posed by and approaches to the study of seasonal-to-decadal climate variability. Clim Change, DOI: $10.1007 / \mathrm{s} 10584-006-9076-8$ (this issue)

Stott P, Kettleborough JA (2002) Origins and estimates of uncertainty in predictions of twenty-first century temperature rise. Nature 416:723-726

Viguier L, Barreto L, Haurie A, Kypreos S, Rafaj P (2006) Modeling endogenous learning and imperfect competition effects in climate change economics. Clim Change, DOI: 10.1007/s10584-006-9070-1 (this issue)

Webster M (2002) The curious role of learning in climate policy: should we wait for more data? Energy $\mathbf{J}$ 23:97-119

Webster M (2003) Communicating climate change uncertainty to policy-makers and the public. Clim Change 61:1-8

Webster M, Forest C, Reilly J, Babiker M, Kicklighter D, Mayer M, Prinn R, Sarofim M, Sokolov A, Stone P, Wang C (2003) Uncertainty analysis of climate change and policy response. Clim Change 61:295-320

Wigley TML, Raper SCB (2001) Interpretations of high projections for global-mean warming. Science 293:451-454

Xoplaki E, Luterbacher J, Paeth H, Dietrich D, Steiner N, Grosjean M, Wanner H (2005) European spring and autumn land temperatures, variability and change of extremes over the last half millennium. Geophys Res Lett 32:L15713

Yoshimori M, Stocker TF, Raible CC, Renold M (2005) Externally-forced and internal variability in ensemble climate simulations of the Maunder Minimum. J Climate 18:4253-4270 